University of Nebraska - Lincoln

DigitalCommons@University of Nebraska - Lincoln

Evaluation of response to bovine viral diarrhea virus type 2 vaccination and timing of weaning on yearling ultrasound body composition, performance, and carcass quality traits in Angus calves

\author{
R. G. Tait Jr \\ lowa State University \\ E. D. Downey \\ lowa State University \\ M. S. Mayes \\ lowa State University \\ C. A. Park \\ lowa State University \\ J. F. Ridpath \\ USDA-ARS
}

See nextpage for additiopal authors

Tait, R. G. Jr; Downey, E. D.; Mayes, M. S.; Park, C. A.; Ridpath, J. F.; Garrick, D. J.; and Reecy, J. M., "Evaluation of response to bovine viral diarrhea virus type 2 vaccination and timing of weaning on yearling ultrasound body composition, performance, and carcass quality traits in Angus calves" (2013).

Publications from USDA-ARS / UNL Faculty. 1407.

https://digitalcommons.unl.edu/usdaarsfacpub/1407

This Article is brought to you for free and open access by the U.S. Department of Agriculture: Agricultural Research Service, Lincoln, Nebraska at DigitalCommons@University of Nebraska - Lincoln. It has been accepted for inclusion in Publications from USDA-ARS / UNL Faculty by an authorized administrator of DigitalCommons@University of Nebraska - Lincoln. 


\section{Authors}

R. G. Tait Jr, E. D. Downey, M. S. Mayes, C. A. Park, J. F. Ridpath, D. J. Garrick, and J. M. Reecy 


\title{
Evaluation of response to bovine viral diarrhea virus type 2 vaccination and timing of weaning on yearling ultrasound body composition, performance, and carcass quality traits in Angus calves ${ }^{1,2,3}$
}

\author{
R. G. Tait Jr., ${ }^{4,5}$ E. D. Downey, ${ }^{* 4}$ M. S. Mayes, ${ }^{*}$ C. A. Park,* J. F. Ridpath, $\dagger$ \\ D. J. Garrick, *\$ and J. M. Reecy*6 \\ *Department of Animal Science, Iowa State University, Ames 50011; ${ }^{\dagger}$ ARS-USDA, National Animal Disease Center, Ames, \\ IA 50010; and \#nstitute of Veterinary, Animal and Biomedical Sciences, Massey University, Palmerston North, New Zealand
}

\begin{abstract}
There are concerns about antagonisms between immunity and animal productivity in livestock production. The objective of this study was to evaluate the effect of antibody levels through a response to vaccination protocol, weaning timing, and their interaction on performance and carcass quality traits in Angus beef cattle. Final antibody level and response to vaccination were based on neutralizing serum antibodies against bovine viral diarrhea virus type 2 (BVDV2). Calves were followed through development and the feedlot phase, with collection of yearling ultrasound $(n=957)$, preharvest $(n=762)$, and carcass $(n=673)$ data. In this study, $48 \%$ of the animals were observed to have positively responded to the vaccine, as evidenced by higher final antibody levels compared to prevaccination antibody levels. Increased final antibody levels were significantly $(P<0.05)$ associated with increased yearling weight and increased subcutaneous fat over the rump. An interaction between final antibody level and weaning time also was associated $(P<0.05)$ with Warner-Bratzler shear force (WBSF) and meat $\mathrm{pH}$, with a favorable, negative relationship between final antibody and WBSF in calves weaned at initial vaccination.
\end{abstract}

Overall antibody response by wean time interaction had a significant $(P<0.05)$ association with ADG and meat $\mathrm{pH}$, with calves weaned at initial vaccination having a favorable, positive relationship between overall antibody response and ADG. Under both the final antibody and overall antibody response models, animals weaned at initial vaccination had significantly $(P<0.05)$ lower intramuscular fat at yearling time and conversely higher harvest weight than animals weaned at the booster vaccination. When antibody response was grouped (none, low, high), a significant interaction $(P<0.05)$ between antibody response group and weaning time was identified for ADG, harvest weight, and HCW. Animals weaned at the initial vaccination in the high antibody response group had the advantage for ADG, harvest weight, and HCW compared to animals in the highresponse group that were weaned at booster vaccination. Linear increases in antibody response generally did not have negative effects on performance or carcass quality traits in finished cattle $(P>0.05)$. Therefore, producers should not be concerned about decreased production or quality attributes as a result of developing a robust antibody response to vaccination for BVDV2 in beef cattle.

Keywords: antibody, beef quality, bovine viral diarrhea virus, cattle, feedlot performance, vaccine response

(C) 2013 American Society of Animal Science. All rights reserved.

This article is a U.S. government work, and is not subject to copyright in the United States.
J. Anim. Sci. 2013.91:5466-5476 doi:10.2527/jas2012-5891

\footnotetext{
${ }^{1}$ This project was funded in part by the Beef Checkoff and the Center for Integrated Animal Genomics at Iowa State University. The authors would like to acknowledge K. Maher, S. Ruble, L. Rossiter, W. Roush, and D. Maxwell at Iowa State University Outlying Demonstration and Research farms for their help with animal care and sample collection. The authors would also like to thank K. McMullen and P. Federico for their technical assistance with training and providing reagents for virus neutralization assays. This study would not have been possible without the help of E. Conrad and $\mathrm{K}$. Lintz conducting virus neutralization assays.
}

\footnotetext{
${ }^{2}$ Mention of trade names or commercial products in this article is solely for the purpose of providing specific information and does not imply recommendation or endorsement by the U.S. Department of Agriculture.

${ }^{3}$ USDA is an equal opportunity provider and employer.

${ }^{4}$ These authors contributed equally to the article.

${ }^{5}$ Present address: ARS-USDA, U.S. Meat Animal Research Center, Clay Center, NE 68933.

${ }^{6}$ Corresponding author: jreecy@iastate.edu

Received September 22, 2012.

Accepted August 10, 2013.
} 


\section{INTRODUCTION}

Bovine respiratory disease (BRD) is among the most detrimental diseases that affect feedlot cattle. It is linked with $75 \%$ of the morbidity and up to $50 \%$ of the mortality in feedlots (Gardner et al., 1999). The predicted annual cost (\$750 million) associated with BRD includes increased treatment costs, increased labor, reduced performance, and carcass losses (Griffin, 1997; Holland et al., 2010). Negative effects of BRD on performance and carcass traits include reduced ADG, BW, HCW, yield grade, LM area, and marbling score (Gardner et al., 1999; Holland et al., 2010; Schneider et al., 2010). Preventive methods, such as vaccination or metaphylaxis to reduce susceptibility, are particularly important during periods of high stress, such as weaning and feedlot transition (Schneider et al., 2009). However, it has been proposed that activation of the immune system may adversely affect growth and performance of animals (Johnson, 1997; Spurlock, 1997). Although Johnson (1997) and Spurlock (1997) report on the effect of proinflammatory cytokines as indicators of immune system activation, another, quite different indicator of immune system activation is high antibody levels after a vaccination protocol. There are few reports available on the relationships between antibody levels and animal performance, warranting further investigation.

This study is an extension of Downey et al. (2013). Where Downey et al. (2013) investigated environmental and management factors influencing the response to vaccination for bovine viral diarrhea virus type 2 (BVDV2), the aim of this study is to determine the effect of antibody response to BVDV2 vaccination, timing of weaning, and their interaction on yearling ultrasound body composition traits, performance traits, and carcass quality traits.

\section{MATERIALS AND METHODS}

All procedures were approved by the Iowa State University Animal Care and Use Committee.

\section{Animal Population}

This study utilized the same 1,004 purebred American Angus calves from the Iowa State University breeding project characterized by Downey et al. (2013) to evaluate the effect of BVDV2 antibody response to vaccination on performance and beef quality traits. Calves were born in 2007, 2008, and 2009 in either of 2 calving seasons, spring or fall.

All calves, regardless of sex, were enrolled in the vaccination protocol $($ males $=548$ and females $=456$ ). The 2009 fall-born bull calves were castrated at birth $(n=$

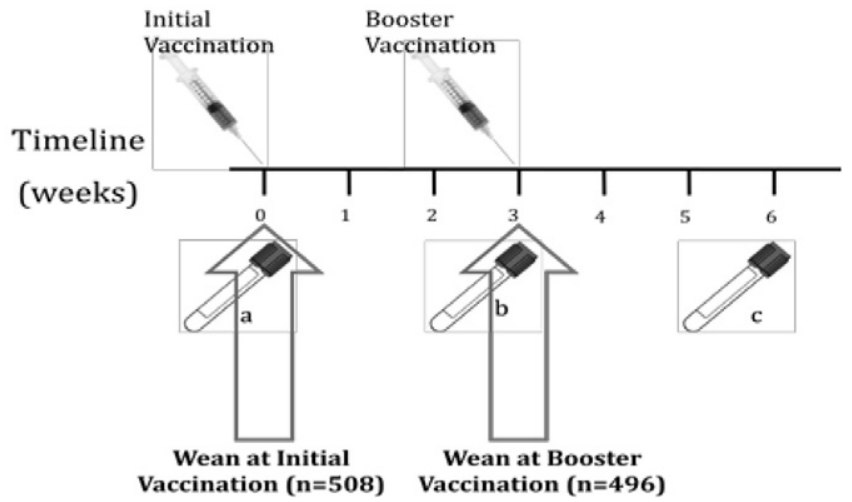

Figure 1. Diagram of serum sample collection (blood tube icon), vaccination timing (syringe icon), and weaning time (large open arrow). The syringes at weeks 0 and 3 indicate time when vaccine was administered to calves. The collection tubes indicate the 3 serum collection time points. (a) Antibody level at initiation of the vaccination protocol $(n=1004)$. (b) Antibody level in calves $3 \mathrm{wk}$ after the initial vaccination, i.e., response to initial vaccination, and time of booster vaccination. (c) Final antibody level achieved following the 2 -shot protocol. The first arrow indicates that half ( $n$ $=508)$ of the calves were weaned at initial vaccination. The second arrow indicates the time of weaning for the second half $(n=496)$ of the calves.

64), while all other male calves were kept intact for the duration of the vaccination/weaning protocol, with approximately half of the males within each year-season maintained as selection candidates and the other half of males castrated on entry into the feedlot after the vaccination protocol.

Spring-born calves ranged from 86 to $205 \mathrm{~d}$ of age when the initial vaccination was administered, with an average age of $149 \mathrm{~d}(\mathrm{SD}=24.5 \mathrm{~d})$. Fall-born calves ranged from 53 to $146 \mathrm{~d}$ of age at the time of initial vaccination, with an average age of $107 \mathrm{~d}(\mathrm{SD}=19.5 \mathrm{~d})$. Calf weights at the time of initial vaccination ranged from 48 to $263 \mathrm{~kg}$, with spring-born calves averaging $163 \mathrm{~kg}(\mathrm{SD}=36.7 \mathrm{~kg})$, and fall-born calves averaging $123 \mathrm{~kg}(\mathrm{SD}=26.4 \mathrm{~kg})$.

\section{Weaning/Vaccination Protocol}

All calves in this study were vaccinated with Bovishield Gold-5 (Zoetis, Kalamazoo, MI). This 5-way vaccine contained modified live antigens against the following viral pathogens: infectious bovine rhinotracheitis, bovine respiratory syncytial virus, parainfluenza-3, bovine viral diarrhea virus type 1 , and BVDV2. The vaccine was administered using a 2-shot protocol, with an average of $21.1 \mathrm{~d}(\mathrm{SD}=2.1 \mathrm{~d})$ between initial $(\mathbf{I})$ vaccination and booster (B) vaccination. Within each year-season, approximately half of the calves were weaned at I $(n=508)$, and the other half of the calves were weaned at B $(n=496$; Fig. 1). The objective of different weaning timings was to identify if timing of weaning stress within the vaccination protocol affected the vaccination response. Calves weaned at I averaged $138.6 \mathrm{~d}(\mathrm{SD}=18.0 \mathrm{~d})$, and calves weaned at 
B averaged $127.6 \mathrm{~d}(\mathrm{SD}=27.4 \mathrm{~d})$ at initiation of the vaccination protocol. Calves were assigned to weaning/vaccination protocol by cow management group within year (spring-born cow group was based on dam age group, fallborn group was based on expected calving date estimated at pregnancy diagnosis). Cow management group (such as dam age group) assignment to weaning/vaccination protocols was varied across years. At weaning, the presence or absence of bovine keratoconjunctivitis infection (Kataria et al., 2011) was recorded.

\section{Response to Vaccination}

Serum Sample Collection. To evaluate response to BVDV2 vaccination, BVDV2 antibody levels were measured in calf serum (Bauermann et al., 2012; Downey et al., 2013). Serum samples for measuring antibody levels were collected at 3 times during the vaccination protocol: 1) just before I (wk 0 sample), 2) at B (wk 3 sample), and 3) 3 wk after B (final, or wk 6 sample; Fig. 1). At each serum collection time point, calf weight $(\mathrm{kg})$ was recorded.

Virus Neutralization. The antibody levels in serum samples that were able to neutralize cytopathic BVDV2 (Singer 296-C strain obtained from National Animal Disease Center, USDA-ARS, Ames, IA) in bovine turbinate cells were determined by virus neutralization assays, as described previously (Bauermann et al., 2012; Downey et al., 2013). For each time point, BVDV2 antibody was recorded as the average log base 2 reciprocal of the highest dilution that neutralized virus across 5 replicates.

Vaccination Response Variable Calculation. Three measures of an individual animal's response to BVDV2 vaccination were used for analyses: 1) final antibody level (total BVDV-neutralizing antibodies present $3 \mathrm{wk}$ after booster vaccination), 2) overall antibody response (final antibody level - initial antibody level), and 3) response level [calves were classified as nonresponders if the antibody response was 0 or less (52\% of population), low responders if the antibody response was greater than 0 but less than or equal to 5 titer units ( $25 \%$ of population), and high responders if the antibody response was greater than 5 titer units (23\% of population)]. Mean antibody titer level and SD for the 3 response groups at each serum collection time point are shown in Fig. 2. It is important to note that response to vaccination and, subsequently, response level are themselves complex traits, influenced by factors such as antibody level at time of vaccination, calf age, and dam age (Downey et al., 2013).

As described by Downey et al. (2013), antibody present at the initiation of the vaccination protocol adversely affects the overall antibody response (and hence response level) and has a quadratic effect on final antibody level. Antibody level at the initiation of a vaccination protocol is affected by age of dam and age of the calf at initial

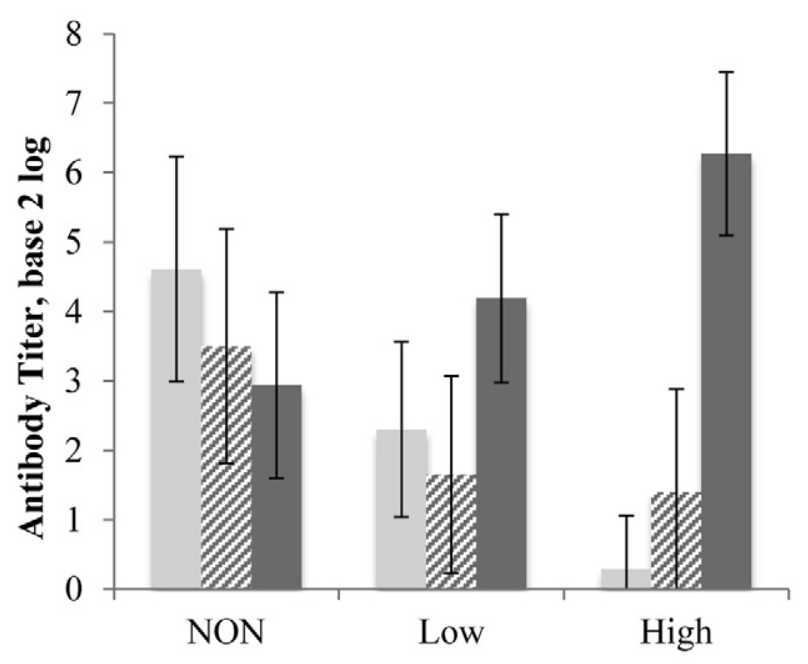

\section{Vaccination Response Group \\ Initial Vaccination \\ ¿ Booster Vaccination \\ - Response to Booster Vaccination}

Figure 2. Antibody titer (base $2 \log$ ) means with SD for vaccination response level (none, low, and high) at the 3 serum collection time points (initial vaccination, $0 \mathrm{wk}$; booster vaccination, $3 \mathrm{wk}$; and response to booster, $6 \mathrm{wk}$ ).

vaccination (Downey et al., 2013). Also, defining nonresponders as not having a higher antibody level after the vaccination than before the initiation of the vaccination does not explicitly mean that the animal did not initiate a humoral response. In the consideration of maternal antibodies declining, a humoral response to the vaccination may have been initiated, but it may not have been enough to exceed the level of maternal antibody decline occurring during the period of the vaccination protocol.

\section{Postweaning Animal Management}

Following the 6-wk vaccination-weaning protocol, calves were sorted by sex for postweaning management. Attrition of data occurred due to animal deaths, selection for breeding, or unsafe weather conditions for collecting phenotypes at outlying research stations. Although management and destination for off-site shipped calves varied slightly among years and seasons, all calves were monitored for symptoms of illness and were treated by farm staff when symptoms of illness were identified in an attempt to reduce the effect of sickness on performance traits. The majority of the males $(n=305)$ were kept intact and were managed as potential replacement herd bulls, with a target weight of approximately 500 $\mathrm{kg}$ at $365 \mathrm{~d}$. Males unlikely to be selection candidates within each year-season $(n=215)$ were castrated after completion of the vaccination protocol (at birth for all males 2009 fall) and were fed a similar diet as the bulls. Steers were not implanted after castration. Twelve bulls 
were selected for breeding during this experiment, with unselected bulls and all steers finished for marketing. All heifers $(n=443)$ were managed postweaning as potential replacements, with a target weight of approximately $65 \%$ of mature weight at the beginning of the breeding season, until yearling performance and ultrasound measures were collected. After yearling performance measures were collected and selection decisions were made, 254 heifers were sent to off-site Iowa State University feedlots for finishing. Carcass data (described later) were only available for those animals finished for marketing.

\section{Yearling Ultrasound Collection}

Ultrasound body composition traits were collected on all calves at approximately yearling age $(n=957)$. Ultrasound images were collected by an Ultrasound Guidelines Council-certified field technician using a Classic Scanner 200 with an ASP-18 transducer (Classic Medical, Tequesta, FL). Ultrasound images were digitized and stored using a BlackBox Image Capturing System (Biotronics Inc., Ames, IA). Ultrasound Guidelines Council-certified laboratory technicians interpreted images and submitted the data to the American Angus Association, which returned the data to Iowa State University. The following ultrasound body composition traits were measured: 1) live weight (held off feed until after data collection; YWT), 2) subcutaneous fat thickness over the termination point of the biceps femoris in the rump (URFAT), 3) subcutaneous fat thickness at 3/4 the lateral distance across the LM between the 12th and 13th ribs (UFAT), 4) LM area between the 12th and 13th ribs (UREA), and 5) percent intramuscular fat within the LM between the 12th and 13th ribs (UPFAT). Docility (6-point scale; Beef Improvement Federation, 2010) was also evaluated at the time yearling ultrasound measures were collected.

\section{Performance Traits}

Preharvest performance and docility data were collected on all market-finished animals within $7 \mathrm{~d}$ before harvest $(n=762)$. Preharvest traits analyzed included 1) BW of the animal (held off feed until after data collection; HWT) and 2) ADG from weaning to harvest [(HWT - weaning weight)/(harvest age - weaning age); $\mathrm{kg} / \mathrm{d}]$.

\section{Carcass Quality Traits}

Cattle finished for marketing were harvested ( $n=$ 673 ) in a commercial facility according to standard industry protocol, and routine carcass measurements were collected by experienced individuals at approximately $24 \mathrm{~h}$ postmortem, including 1) $\mathrm{HCW}, 2$ ) subcutaneous fat thickness at 3/4 the lateral distance across the LM between the 12th and 13th ribs (CFAT), 3) LM area measured using plastic dot grid overlay between the 12th and 13th ribs (CREA), 4) estimated percent kidney, pelvic, and heart fat (CKPH), and 5) USDA marbling score (MARB) to the nearest 10 marbling score units $(3.00=$ Traces $^{00}, 4.00=$ Slight $^{00}, 5.00=$ Small $^{00}, 6.00=$ Modest $^{00}, 7.00=$ Moderate $^{00}, 8.00=$ Slightly Abundant ${ }^{00}$, and $9.00=$ Moderately Abundant ${ }^{00}$ ). Fat thickness over the 12th rib was only adjusted if there was an obvious disruption of the fat thickness at the location of measurement, but overall fat distribution of the carcass was not used as an adjustment criterion for fat thickness over the 12th rib. Yield grade (YG) was calculated from these carcass measurements as follows: $\mathrm{YG}=2.5+(0.984 \times$ CFAT, cm $)+(0.2 \times \mathrm{CKPH}, \%)+(0.0084 \times \mathrm{HCW}, \mathrm{kg})$ $-\left(0.05 \times\right.$ CREA, $\left.\mathrm{cm}^{2}\right)$. Animals were harvested as a single group for each combination of year, season, and yearling sex group; therefore, harvest date was not included in subsequent analyses as it was confounded with contemporary group. Approximately $48 \mathrm{~h}$ after harvest, ultimate $\mathrm{pH}$ was measured on a sample of LM near the 12 th to 13 th rib interface $(n=667)$.

\section{Warner-Bratzler Shear Force}

A 2.54-cm-thick LM steak was prepared for WarnerBratzler shear force (WBSF; $n=592$ ) evaluation. All steaks were vacuum packaged, aged for $14 \mathrm{~d}$ from the harvest date at $2^{\circ} \mathrm{C}$, then frozen at $-20^{\circ} \mathrm{C}$ until subsequent analysis. At a later date, the frozen steaks were allowed to thaw at $4^{\circ} \mathrm{C}$ for $24 \mathrm{~h}$ before cooking. Steaks were broiled to an internal temperature of $71.1^{\circ} \mathrm{C}$. After cooking, steaks were cooled at room temperature for at least $4 \mathrm{~h}$. Six cores, $1.27 \mathrm{~cm}$ in diameter, were removed perpendicular to the surface of the steak and sheared once, using a Warner-Bratzler head attached to a TA-XT2i Texture Analyzer (Texture Technologies Corp., Searsdale, NY). The Warner-Bratzler shear attachment crosshead moved at a speed of $200 \mathrm{~mm} / \mathrm{min}$. Peak force $(\mathrm{kg})$ to shear each core was recorded using Texture Analysis Exponent Software (version 5.0.8.0, Texture Technologies Corp.). Mean peak force (kg) of the 6 cores was the trait analyzed for each sample.

\section{Statistical Analysis}

Statistical analyses were performed using the GLM procedure in SAS version 9.2 (SAS Inst. Inc., Cary, NC). The effects of vaccination response traits (final antibody level, overall antibody response, or response level), weaning time (wean time), and their interaction on yearling ultrasound traits (YWT, URFAT, UFAT, UREA, and UPFAT), performance traits (HWT and ADG from wean- 
ing to harvest), and carcass traits (HCW, CFAT, CREA, CKPH, MARB, YG, $\mathrm{pH}$, and WBSF) were examined.

The following general model was used for each of the 3 vaccination response trait analyses on phenotypes of interest:

$$
\begin{aligned}
& \mathrm{y}_{i j k l m n o p}=\mu+\mathrm{R}_{i}+\mathrm{W}_{j}+\mathrm{R}_{i} \times \mathrm{W}_{j}+\mathrm{CG}_{k} \\
& +\mathrm{DA}_{i}+\mathrm{PE}_{m}+\mathrm{Doc}_{n}+\mathrm{A}_{p}\left(\mathrm{Sex}_{o}\right)+\mathrm{e}_{i j k l m n o p},
\end{aligned}
$$

where $\mathrm{y}_{\text {ijklmnop }}=$ ultrasound, performance, or carcass quality trait measured on calf $\mathrm{p} ; \mathrm{R}_{i}=$ antibody response variable, 1) final antibody level fit as a covariate, 2) overall antibody response fit as a covariate, or 3) response level $(i=$ nonresponder, low responder, or high responder) fit as a class effect; $\mathrm{W}_{j}=$ weaning time $(j=\mathrm{I}$ or $\mathrm{B})$; $\mathrm{R}_{i} \times \mathrm{W}_{j}=$ antibody response variable by weaning time interaction. $\mathrm{CG}_{k}=$ postweaning management contemporary group (year, season, sex, and management group; $k$ $=1$ to 21 groups) fit as a class effect; $\mathrm{DA}_{l}=$ dam age $(l=$ 2 to $11 \mathrm{yr}$ old) fit as a class effect; $\mathrm{PE}_{m}=$ pinkeye classification at weaning ( $m=0$ or 1$)$ fit as a class effect; $\operatorname{Doc}_{n}$ $=$ docility score $(n=1$ to 6$)$ fit as a class effect (for yearling ultrasound traits, docility score at yearling scanning was used; for performance and carcass traits, preharvest docility score was used). $A_{p}\left(\operatorname{Sex}_{o}\right)=$ covariate effect of calf age $(\mathrm{d}$; yearling age for yearling ultrasound traits, preharvest age for ADG and HWT, and age at harvest for carcass traits) nested within yearling sex $\left(\operatorname{Sex}_{o}=\right.$ bulls, steers, or heifers). The error term $\left(\mathrm{e}_{i j k l m o p}\right)$ is assumed to be normally distributed with mean $=0$ and variance $=$ $\sigma_{\mathrm{e}}^{2}$. Variables were sequentially removed on the basis of nonsignificance $(P>0.05)$ from the model for each trait evaluated within each vaccine response trait analysis.

\section{RESULTS AND DISCUSSION}

Animals in this study were managed to typical U.S. beef industry end points. Table 1 presents means and standard deviations for age and traits by sex, which presents the variability in growth and age at end point by sex. Significant effects for yearling ultrasound, performance, and carcass quality traits have been presented for the final antibody level, overall antibody response, and response level analyses in Tables 2, 3, and 4, respectively.

The contemporary group animals were managed within affected $(P<0.01)$ all-yearling ultrasound, performance, and carcass quality traits (Tables 2, 3, and $4)$. The contemporary group effect was highly variable across the 21 management groups, with similar effects seen within ultrasound, performance, and carcass quality traits and across antibody response models (final antibody level, overall antibody response, and response level; data not shown). For all of the performance traits
Table 1. Means with standard deviation and animal counts are listed for all yearling ultrasound, growth per-

\begin{tabular}{|c|c|c|c|c|c|c|}
\hline \multirow[b]{2}{*}{ Traits $^{1}$} & \multicolumn{2}{|r|}{ Bulls } & \multicolumn{2}{|r|}{ Steers } & \multicolumn{2}{|r|}{ Heifers } \\
\hline & $n$ & Mean (SD) & $n$ & Mean (SD) & $n$ & Mean (SD) \\
\hline \multicolumn{7}{|c|}{ Yearling ultrasound } \\
\hline YAge, $\mathrm{d}$ & 302 & $372.0(20.4)$ & 212 & $378.1(20.8)$ & 443 & $399.8(16.7)$ \\
\hline YWT, kg & 302 & $461.8(52.9)$ & 212 & $439.0(51.1)$ & 443 & $321.1(46.8)$ \\
\hline URFAT, $\mathrm{cm}$ & 301 & $0.71(0.20)$ & 212 & $0.89(0.23)$ & 443 & $0.53(0.20)$ \\
\hline UFAT, cm & 302 & $0.69(0.23)$ & 212 & $0.91(0.23)$ & 443 & $0.46(0.18)$ \\
\hline UREA, $\mathrm{cm}^{2}$ & 302 & $74.8(10.0)$ & 212 & $71.6(7.9)$ & 443 & $50.7(7.8)$ \\
\hline UPFAT, $\%$ & 302 & $4.5(0.9)$ & 212 & $5.5(1.1)$ & 443 & $4.9(1.2)$ \\
\hline \multicolumn{7}{|l|}{ Performance } \\
\hline HAge, d & 292 & $434.6(38.4)$ & 215 & $445.1(23.3)$ & 254 & $578.3(46.2)$ \\
\hline HWT, kg & 292 & $551.1(46.4)$ & 215 & $513.9(58.0)$ & 254 & $521.6(56.1)$ \\
\hline $\mathrm{ADG}, \mathrm{kg} / \mathrm{d}$ & 292 & $1.41(0.17)$ & 215 & $1.22(0.15)$ & 254 & $0.86(0.13)$ \\
\hline \multicolumn{7}{|l|}{ Carcass } \\
\hline $\mathrm{HCW}, \mathrm{kg}$ & 257 & $337.6(33.7)$ & 209 & $316.0(36.0)$ & 207 & $315.5(38.9)$ \\
\hline CFAT, cm & 257 & $1.0(0.25)$ & 209 & $1.1(0.28)$ & 207 & $1.3(0.33)$ \\
\hline CREA, $\mathrm{cm}^{2}$ & 257 & $83.1(7.0)$ & 209 & $76.9(6.0)$ & 207 & $78.8(7.5)$ \\
\hline СКРН, \% & 257 & $1.9(0.50)$ & 209 & $2.2(0.46)$ & 207 & $2.3(0.51)$ \\
\hline MARB & 257 & $5.62(0.98)$ & 209 & $6.54(1.04)$ & 207 & $6.87(1.08)$ \\
\hline YG & 257 & $2.58(0.50)$ & 209 & $2.89(0.46)$ & 207 & $2.96(0.52)$ \\
\hline WBSF, $\mathrm{kg}$ & 228 & $3.608(0.976)$ & 177 & $3.340(0.831)$ & 187 & $3.396(1.088)$ \\
\hline $\mathrm{pH}$ & 255 & $5.71(0.33)$ & 206 & $5.50(0.08)$ & 206 & $5.48(0.15)$ \\
\hline
\end{tabular}
formance, and carcass composition traits

${ }^{1}$ YAge $=$ calf age at yearling ultrasound data collection; $\mathrm{YWT}=$ yearling live weight at ultrasound collection; URFAT = subcutaneous fat thickness over the termination point of the biceps femoris in the rump; UFAT = subcutaneous fat thickness at 3/4 the lateral distance across the LM between the 12th and 13th ribs; UREA $=$ LM area between 12th and 13th ribs; UPFAT $=$ percent intramuscular fat within the LM between the 12th and 13th ribs; HAge = age at collection of harvest live WT; HWT $=$ live harvest weight 1 to $7 \mathrm{~d}$ before harvest; $\mathrm{ADG}=\mathrm{ADG}$ between weaning and harvest $[(\mathrm{HWT}-$ weaning wt $) /$ (harvest age - weaning age)]; CFAT $=$ subcutaneous fat thickness at $3 / 4$ the lateral distance across the LM between the 12th and 13th ribs; CREA $=$ LM area using plastic dot grid overlay between the 12th and 13th ribs; $\mathrm{CKPH}=$ estimated percent kidney, pelvic, and heart fat; $\mathrm{MARB}=$ marbling score to the nearest 10 marbling score units $\left(3.00=\right.$ Traces $^{00}, 4.00=$ Slight $^{00}, 5.00=$ Small $^{00}, 6.00=$ Modest $^{00}, 7.00=$ Moderate ${ }^{00}, 8.00=$ Slightly Abundant ${ }^{00}$, and $9.00=$ Moderately Abundant $\left.{ }^{00}\right) ; \mathrm{YG}=$ yield grade calculated $[\mathrm{YG}=2.5$ $+(0.984 \times$ CFAT, $\mathrm{cm})+(0.2 \times \mathrm{CKPH}, \%)+(0.0084 \times \mathrm{HCW}, \mathrm{kg})-(0.05 \times$ CREA, $\left.\mathrm{cm}^{2}\right)$ ]; WBSF $=$ Warner-Bratzler shear force.

evaluated in this study across the 3 vaccination response traits, factors such as dam age, pinkeye incidence at weaning, docility of the calf, and age nested within sex are included beyond the contemporary group in the models to adjust for the expected effects of these factors. The focus of the study is on the effects of response to vaccination traits, weaning timing, and their interaction on the performance traits.

\section{Response to Vaccination Trait Effects on Yearling Ultrasound Traits}

Final antibody level had a significant $(P<0.05)$ positive association on YWT (Table 2). YWT increased as final antibody levels increased, e.g., for every 1 unit 
Table 2. Model $R^{2}$ and significance ( $P$-values) for fixed sources of variation when analyzing yearling ultrasound, growth performance, and carcass composition traits with final antibody level as the response to vaccination trait ${ }^{1}$

\begin{tabular}{|c|c|c|c|c|c|c|c|c|c|}
\hline \multirow[b]{2}{*}{ Traits $^{2}$} & \multirow[b]{2}{*}{$R^{2}$} & \multicolumn{8}{|c|}{ Final antibody level model significance } \\
\hline & & $\mathrm{R}$ & $\mathrm{W}$ & $\mathrm{R} \times \mathrm{W}$ & CG & $\mathrm{DA}$ & $\mathrm{PE}$ & Doc & $\mathrm{A}(\mathrm{Sex})$ \\
\hline \multicolumn{10}{|c|}{ Yearling ultrasound } \\
\hline URFAT, $\mathrm{cm}$ & 0.54 & $<0.01$ & - & - & $<0.01$ & $<0.01$ & 0.01 & - & $<0.01^{3}$ \\
\hline UFAT, cm & 0.62 & - & - & - & $<0.01$ & $<0.01$ & - & - & $<0.01^{3}$ \\
\hline UREA, $\mathrm{cm}^{2}$ & 0.80 & - & - & - & $<0.01$ & - & 0.01 & - & $<0.01^{3}$ \\
\hline \multicolumn{10}{|l|}{ Performance } \\
\hline HWT, kg & 0.45 & - & $<0.01$ & - & $<0.01$ & - & - & $<0.01$ & $<0.01^{4}$ \\
\hline $\mathrm{ADG}, \mathrm{kg} / \mathrm{d}$ & 0.82 & - & - & - & $<0.01$ & - & 0.02 & $<0.01$ & - \\
\hline \multicolumn{10}{|l|}{ Carcass } \\
\hline $\mathrm{HCW}, \mathrm{kg}$ & 0.42 & - & - & - & $<0.01$ & $<0.01$ & - & - & $<0.01^{5}$ \\
\hline CFAT, cm & 0.33 & - & - & - & $<0.01$ & 0.05 & - & - & $<0.01^{5}$ \\
\hline YG & 0.32 & - & - & - & $<0.01$ & - & - & - & $<0.01^{5}$ \\
\hline WBSF, $\mathrm{kg}$ & 0.51 & & & $0.02^{6}$ & $<0.01$ & - & - & - & - \\
\hline $\mathrm{pH}$ & 0.40 & & & $<0.01^{6}$ & $<0.01$ & $<0.01$ & - & - & - \\
\hline
\end{tabular}

- Nonsignificant $(P>0.05)$ effects in the model.

${ }^{1} R^{2}=$ proportion of variance accounted for the model with significant effects $(P<0.05)$ as listed. $\mathrm{R}=$ final antibody level; $\mathrm{W}=$ weaning time $($ at initial vaccination or booster vaccination); $\mathrm{R} \times \mathrm{W}=$ interaction between final antibody level and weaning time; $\mathrm{CG}=$ postweaning management group (year, season, sex, and management group; $n=21 \mathrm{CG}$ groups); DA = dam age (yr, 2 to 11$) ; \mathrm{PE}=$ pinkeye (0 or 1); Doc = docility score (6-point scale; yearling docility used for yearling ultrasound traits, preharvest docility score used for performance and carcass traits); $\mathrm{A}(\mathrm{Sex})=$ age (d; yearling age for yearling ultrasound traits, preharvest age for ADG and HWT, and age at harvest for carcass traits) nested within postweaning sex (bulls, steers, or heifers). W, CG, DA, PE, and Doc were fit as class effects.

${ }^{2}$ YWT = yearling live weight at ultrasound collection; URFAT = subcutaneous fat thickness over the termination point of the biceps femoris in the rump; UFAT $=$ subcutaneous fat thickness at 3/4 the lateral distance across the LM between the 12th and 13th ribs; UREA $=$ LM area between 12th and 13th ribs; UPFAT = percent intramuscular fat within the LM between the 12th and 13th ribs; HWT = live harvest weight within $7 \mathrm{~d}$ before harvest; $\mathrm{ADG}=\mathrm{ADG}$ between weaning and harvest [(HWT - weaning WT)/(harvest age - weaning age)]; CFAT = subcutaneous fat thickness at 3/4 the lateral distance across the LM between the 12 th and 13th ribs; CREA = LM area using plastic dot grid overlay between the 12th and 13th ribs; CKPH = estimated percent kidney, pelvic, and heart fat; MARB $=$ marbling score to the nearest 10 marbling score units $\left(3.00=\right.$ Traces $^{00}, 4.00=$ Slight $^{00}, 5.00=$ Small $^{00}, 6.00=$ Modest $^{00}, 7.00=$ Moderate $^{00}, 8.00=$ Slightly Abundant ${ }^{00}$, and $9.00=$ Moderately Abundant $\left.{ }^{00}\right) ; \mathrm{YG}=$ yield grade calculated $[\mathrm{YG}=2.5+(0.984 \times \mathrm{CFAT}, \mathrm{cm})+(0.2 \times \mathrm{CKPH}, \%)+(0.0084 \times \mathrm{HCW}, \mathrm{kg})-$ $\left(0.05 \times\right.$ CREA, $\left.\left.\mathrm{cm}^{2}\right)\right]$; WBSF $=$ Warner-Bratzler shear force .

${ }^{3}$ YAge $=$ animal age $(\mathrm{d})$ at yearling ultrasound data collection.

${ }^{4}$ PreAge $=$ animal age $(\mathrm{d})$ at collection of HWT (collection of performance data, $<7 \mathrm{~d}$ before harvest).

${ }^{5} \mathrm{HAge}=$ animal age $(\mathrm{d})$ at harvest.

${ }^{6} \mathrm{When} \mathrm{R} \times \mathrm{W}$ is significant $(P<0.05), P$-values for $\mathrm{R}$ and $\mathrm{W}$ main effects are not presented.

increase in final antibody level, YWT increased by 1.65 $\pm 0.72 \mathrm{~kg}$. However, neither overall antibody response nor response level significantly affected YWT $(P>0.05$; Tables 3 and 4). Maintaining a high antibody level after vaccination (final titer) did not adversely affect performance by repartitioning resources away from growth processes. This is consistent with the findings of Martin et al. (1999), who found a positive association between BVDV titers at arrival and weight gain in the first $28 \mathrm{~d}$ at the feedlot.

Final antibody level had a significant $(P<0.01)$ association with URFAT (Table 2); with every 1-unit increase in final antibody level, URFAT increased by $0.008 \pm 0.003 \mathrm{~cm}$. Additionally, response level had a significant $(P<0.05)$ association with URFAT (Table
4). Interestingly, nonresponders and low responders were significantly different $(P<0.05)$ from each other (Fig. 3); low responders had more URFAT $(0.62 \pm 0.038$ $\mathrm{cm})$, whereas nonresponders had the least URFAT $(0.58$ $\pm 0.037 \mathrm{~cm})$. None of the antibody response variables (final antibody level, overall antibody response, or response level), weaning time, or their interaction had a significant association on UFAT or UREA $(P>0.05$; Tables 2, 3, and 4).

\section{Response to Vaccination Trait Effects on Performance Traits}

Neither final antibody level nor its interaction with weaning time had a significant association with perfor- 
Table 3. Model $R^{2}$ and significance ( $P$-values) for fixed sources of variation when analyzing yearling ultrasound, growth performance, and carcass composition traits with overall antibody response as the response to vaccination $\operatorname{trait}^{1}$

\begin{tabular}{|c|c|c|c|c|c|c|c|c|c|}
\hline \multirow[b]{2}{*}{ Trait $^{2}$} & \multirow[b]{2}{*}{$R^{2}$} & \multicolumn{8}{|c|}{ Overall antibody response model significance } \\
\hline & & $\mathrm{R}$ & $\mathrm{W}$ & $\mathrm{R} \times \mathrm{W}$ & CG & DA & PE & Doc & $\mathrm{A}(\mathrm{Sex})$ \\
\hline \multicolumn{10}{|c|}{ Yearling Ultrasound } \\
\hline URFAT, cm & 0.54 & - & - & - & $<0.01$ & $<0.01$ & $<0.01$ & - & $<0.01^{3}$ \\
\hline UFAT, $\mathrm{cm}$ & 0.62 & - & - & - & $<0.01$ & $<0.01$ & - & - & $<0.01^{3}$ \\
\hline UREA, $\mathrm{cm}^{2}$ & 0.80 & - & - & - & $<0.01$ & - & 0.01 & - & $<0.01^{3}$ \\
\hline \multicolumn{10}{|l|}{ Performance } \\
\hline HWT, kg & 0.45 & - & $<0.01$ & - & $<0.01$ & - & - & $<0.01$ & $<0.01^{4}$ \\
\hline $\mathrm{ADG}, \mathrm{kg} / \mathrm{d}$ & 0.82 & & & $0.04^{6}$ & $<0.01$ & - & 0.01 & $<0.01$ & - \\
\hline \multicolumn{10}{|l|}{ Carcass } \\
\hline $\mathrm{HCW}, \mathrm{kg}$ & 0.42 & - & - & - & $<0.01$ & $<0.01$ & - & - & $<0.01^{5}$ \\
\hline CFAT, cm & 0.33 & - & - & - & $<0.01$ & 0.05 & - & - & $<0.01^{5}$ \\
\hline YG & 0.32 & - & - & - & $<0.01$ & - & - & - & $<0.01^{5}$ \\
\hline WBSF, kg & 0.50 & - & - & - & $<0.01$ & - & - & - & - \\
\hline $\mathrm{pH}$ & 0.40 & & & $0.03^{6}$ & $<0.01$ & 0.03 & - & - & - \\
\hline
\end{tabular}

- Nonsignificant $(P>0.05)$ effects in the model.

${ }^{1} R^{2}=$ proportion of variance accounted for in the model with significant effects $(P<0.05)$ as listed. $R=$ overall antibody response (final antibody level - initial antibody level); $\mathrm{W}=$ weaning time [initial (I) or booster (B)]; $\mathrm{R} \times \mathrm{W}=$ interaction between overall antibody response and weaning time; $\mathrm{CG}=$ postweaning management group (year, season, sex, and management group; $n=21 \mathrm{CG}$ groups); DA = dam age (yr, 2 to 11$)$; PE = pinkeye $(0$ or 1$)$; Doc $=$ docility score (6-point scale; yearling docility used for yearling ultrasound traits, preharvest docility score used for performance and carcass traits); $\mathrm{A}(\mathrm{Sex})=\mathrm{age}(\mathrm{d}$; yearling age for yearling ultrasound traits, preharvest age for ADG and HWT, and age at harvest for carcass traits) nested within postweaning sex. W, CG, DA, PE, and Doc were fit as class effects.

${ }^{2} \mathrm{YWT}=$ yearling live weight at ultrasound collection; URFAT = subcutaneous fat thickness over the termination point of the biceps femoris in the rump; UFAT $=$ subcutaneous fat thickness at $3 / 4$ the lateral distance across the LM between the 12th and 13th ribs; UREA $=$ LM area between 12th and 13th ribs; UPFAT $=$ percent intramuscular fat within the LM between the 12th and 13th ribs; HWT = live harvest weight 1 to $7 \mathrm{~d}$ before harvest; $\mathrm{ADG}=\mathrm{ADG}$ between weaning and harvest [(HWT - weaning WT)/(harvest age - weaning age)]; CFAT = subcutaneous fat thickness at 3/4 the lateral distance across the LM between the 12th and 13th ribs; CREA $=$ LM area using plastic dot grid overlay between the 12th and 13th ribs; CKPH = estimated percent kidney, pelvic, and heart fat; MARB $=$ marbling score to the nearest 10 marbling score units $\left(3.00=\right.$ Traces $^{00}, 4.00=$ Slight $^{00}, 5.00=$ Small $^{00}, 6.00=$ Modest $^{00}, 7.00=$ Moderate $^{00}, 8.00=$ Slightly $^{0}$ Abundant ${ }^{00}$, and $9.00=$ Moderately Abundant $\left.{ }^{00}\right) ; \mathrm{YG}=$ yield grade calculated $[\mathrm{YG}=2.5+(0.984 \times \mathrm{CFAT}, \mathrm{cm})+(0.2 \times \mathrm{CKPH}, \%)+(0.0084 \times \mathrm{HCW}, \mathrm{kg})-$ $\left(0.05 \times\right.$ CREA, $\left.\left.\mathrm{cm}^{2}\right)\right]$; WBSF $=$ Warner-Bratzler shear force .

${ }^{3}$ YAge $=$ animal age $(\mathrm{d})$ at yearling ultrasound data collection.

${ }^{4}$ PreAge $=$ animal age $(\mathrm{d})$ at collection of HWT (collection of performance data, $<7 \mathrm{~d}$ before harvest).

${ }^{5} \mathrm{HAge}=$ animal age $(\mathrm{d})$ at harvest.

${ }^{6} \mathrm{When} \mathrm{R} \times \mathrm{W}$ is significant $(P<0.05), P$-values for $\mathrm{R}$ and $\mathrm{W}$ main effects are not presented.

mance traits $(P>0.05$; Table 2$)$, indicating that animals with higher antibody levels after a double-vaccination regimen do not appear to have compromised growth rates.

The interaction between overall antibody response and weaning was significantly associated $(P<0.05)$ with ADG (Table 3 ). The ADG of animals in the wean at I vaccination group increased $0.0052 \pm 0.0023 \mathrm{~kg} / \mathrm{d}$ per 1 -unit increase in overall antibody response $(P=0.02)$. In contrast, there was not a significant association $(P=0.85)$ between ADG and overall antibody response in the wean at $\mathrm{B}$ group, which was estimated at $-0.0004 \pm 0.0021$ $\mathrm{kg} / \mathrm{d}$ per 1-unit increase in overall antibody response.

The interaction between response level (nonresponders, low responders, and high responders) and weaning time was significantly $(P<0.05)$ associ- ated with ADG and HWT (Table 4 and Fig. 4 and 5). High-responder calves that were weaned at initial vaccination gained significantly $(P<0.05)$ faster than all nonresponder calves, low responders weaned at initial vaccination, and high responders weaned at booster vaccination (Fig. 4). Although the high responders weaned at initial vaccination had the numerically highest ADG, they were not significantly different $(P>0.05)$ from low-responder calves weaned at booster vaccination. Although an interaction between response classification group and timing of weaning exists for $\mathrm{ADG}$, the fact that the nonresponders were consistently the slowestgaining cattle does not support the concept of high antibody response being antagonistic toward growth, where 
Table 4. Model $R^{2}$ and significance ( $P$-values) for fixed sources of variation when analyzing yearling ultrasound, growth performance, and carcass composition traits with response level (nonresponders, low responders, or high responders) as the response to vaccination trait ${ }^{1}$

\begin{tabular}{|c|c|c|c|c|c|c|c|c|c|}
\hline \multirow[b]{2}{*}{ Trait $^{2}$} & \multirow[b]{2}{*}{$R^{2}$} & \multicolumn{8}{|c|}{ Response level model significance } \\
\hline & & $\mathrm{R}$ & $\mathrm{W}$ & $\mathrm{R} \times \mathrm{W}$ & CG & $\mathrm{DA}$ & $\mathrm{PE}$ & Doc & $\mathrm{A}(\mathrm{Sex})$ \\
\hline \multicolumn{10}{|c|}{ Yearling Ultrasound } \\
\hline YWT, kg & 0.82 & - & - & - & $<0.01$ & $<0.01$ & 0.02 & - & $<0.01^{3}$ \\
\hline URFAT, $\mathrm{cm}$ & 0.54 & 0.02 & - & - & $<0.01$ & $<0.01$ & $<0.01$ & - & $<0.01^{3}$ \\
\hline UFAT, $\mathrm{cm}$ & 0.62 & - & - & - & $<0.01$ & $<0.01$ & - & - & $<0.01^{3}$ \\
\hline UREA, $\mathrm{cm}^{2}$ & 0.80 & - & - & - & $<0.01$ & - & 0.01 & - & $<0.01^{3}$ \\
\hline UPFAT, \% & 0.25 & - & 0.01 & - & $<0.01$ & - & - & - & $<0.01^{3}$ \\
\hline \multicolumn{10}{|l|}{ Performance } \\
\hline HWT, kg & 0.46 & & & $0.03^{6}$ & $<0.01$ & - & - & $<0.01$ & $<0.01^{4}$ \\
\hline $\mathrm{ADG}, \mathrm{kg} / \mathrm{d}$ & 0.82 & & & $<0.01^{6}$ & $<0.01$ & - & 0.02 & $<0.01$ & - \\
\hline \multicolumn{10}{|l|}{ Carcass } \\
\hline $\mathrm{HCW}, \mathrm{kg}$ & 0.43 & & & $0.03^{6}$ & $<0.01$ & $<0.01$ & - & - & $<0.01^{5}$ \\
\hline CFAT, cm & 0.33 & - & - & - & $<0.01$ & 0.05 & - & - & $<0.01^{5}$ \\
\hline CREA, $\mathrm{cm}^{2}$ & 0.29 & - & - & - & $<0.01$ & - & - & - & $<0.01^{5}$ \\
\hline СКРН, \% & 0.24 & - & - & - & $<0.01$ & - & - & - & $0.03^{5}$ \\
\hline MARB & 0.42 & - & - & - & $<0.01$ & - & - & - & $<0.01^{5}$ \\
\hline YG & 0.32 & - & - & - & $<0.01$ & - & - & - & $<0.01^{5}$ \\
\hline WBSF, $\mathrm{kg}$ & 0.50 & - & - & - & $<0.01$ & - & - & - & - \\
\hline $\mathrm{pH}$ & 0.39 & - & - & - & $<0.01$ & 0.04 & - & - & - \\
\hline
\end{tabular}

-Nonsignificant $(P>0.05)$ effects in the model.

${ }^{1} R^{2}=$ proportion of variance accounted for the model with significant effects $(P<0.05)$ as listed. $\mathrm{R}=$ response level (nonresponders, low responders, and high responders); $\mathrm{W}=$ weaning time (at initial vaccination or booster vaccination); $\mathrm{R} \times \mathrm{W}=$ interaction between response level and weaning time; $\mathrm{CG}=$ postweaning management group (year, season, sex, and management group; $n=21 \mathrm{CG}$ groups); DA = dam age (yr, 2 to 11$)$; PE = pinkeye (0 or 1$)$; Doc = docility score (6-point scale; yearling docility used for yearling ultrasound traits, preharvest docility score used for performance and carcass traits); A(Sex) = age (d; yearling age for yearling ultrasound traits, preharvest age for ADG and HWT, and age at harvest for carcass traits) nested within postweaning sex. R, W, R $\times$ W, CG, DA, PE, and Doc were fit as class effects.

${ }^{2}$ YWT = yearling live weight at ultrasound collection; URFAT = subcutaneous fat thickness over the termination point of the biceps femoris in the rump; UFAT $=$ subcutaneous fat thickness at 3/4 the lateral distance across the LM between the 12th and 13th ribs; UREA $=$ LM area between 12th and 13th ribs; UPFAT $=$ percent intramuscular fat within the LM between the 12th and 13th ribs; HWT $=$ live harvest weight 1 to $7 \mathrm{~d}$ before harvest; $\mathrm{ADG}=\mathrm{ADG}$ between weaning and harvest [(HWT - weaning WT)/(harvest age - weaning age)]; CFAT = subcutaneous fat thickness at 3/4 the lateral distance across the LM between the 12 th and 13th ribs; CREA = LM area using plastic dot grid overlay between the 12th and 13th ribs; CKPH = estimated percent kidney, pelvic, and heart fat; MARB $=$ marbling score to the nearest 10 marbling score units $\left(3.00=\right.$ Traces $^{00}, 4.00=$ Slight $^{00}, 5.00=$ Small $^{00}, 6.00=$ Modest $^{00}, 7.00=$ Moderate $^{00}, 8.00=$ Slightly Abundant ${ }^{00}$, and $9.00=$ Moderately Abundant $\left.{ }^{00}\right) ; \mathrm{YG}=$ yield grade calculated $[\mathrm{YG}=2.5+(0.984 \times \mathrm{CFAT}, \mathrm{cm})+(0.2 \times \mathrm{CKPH}, \%)+(0.0084 \times \mathrm{HCW}, \mathrm{kg})-$ $\left(0.05 \times\right.$ CREA, $\left.\left.\mathrm{cm}^{2}\right)\right]$; WBSF $=$ Warner-Bratzler shear force.

${ }^{3}$ YAge $=$ animal age $(\mathrm{d})$ at yearling ultrasound data collection .

${ }^{4}$ PreAge $=$ animal age $(\mathrm{d})$ at collection of HWT (collection of performance data, $<7 \mathrm{~d}$ before harvest).

${ }^{5} \mathrm{HAge}=$ animal age $(\mathrm{d})$ at harvest.

${ }^{6} \mathrm{When} \mathrm{R} \times \mathrm{W}$ is significant $(P<0.05), P$-values for $\mathrm{R}$ and $\mathrm{W}$ main effects are not presented.

the cytokine immune responses observed by Johnson (1997) and Spurlock (1997) were antagonistic.

The analysis of response level effect interaction with weaning time effect on HWT revealed that all animals weaned at initial vaccination were in the heaviest HWT group (Fig. 5). Interestingly, although animals that were high responders and weaned at initial vaccination had the heaviest HWT, high responders weaned at booster vaccination had the lowest HWT $(P<0.05$; Fig. 5). This dynamic effect on HWT within the high-responder group of animals based on the timing of weaning is similar in direction to early weaning studies such as Meyer et al. (2005) even though the differences in weaning in our study are only about $12 \%$ of the difference in weaning strategies investigated by Meyer et al. (2005).

\section{Response to Vaccination Trait Effects on Carcass Quality Traits}

The only carcass quality traits that were significantly $(P<0.05)$ associated with final antibody level and weaning time were WBSF and $\mathrm{pH}$ (Table 2), where there were interactions indicating a difference in relationship between final antibody level and these traits dependent on when weaning occurred. In animals weaned at initial vaccination, $\mathrm{pH}$ went up $0.011( \pm 0.0068)$ per unit of final antibody level $(P=0.08)$. However, animals weaned 


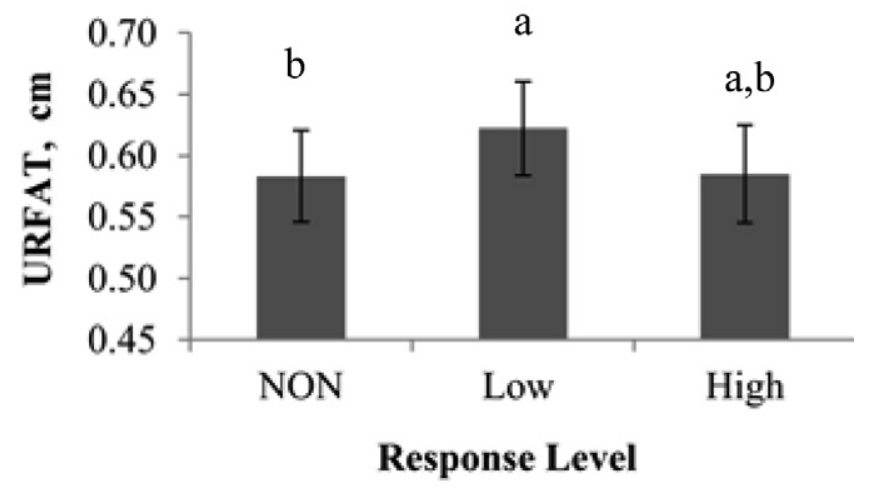

Figure 3. Least squares means of ultrasound measured subcutaneous rump fat thickness (URFAT; $\mathrm{cm}$ ) based on response level (non, low, and high). Least squares means with different letters are statistically different $(P<0.05)$.

at booster vaccination had a $\mathrm{pH}$ change at -0.016 $( \pm 0.0068)$ per unit of final antibody level $(P=0.02)$.

There was no significant association $(P=0.36)$ between final antibody level and WBSF, $(0.019 \pm 0.021$ $\mathrm{kg} /$ titer unit) in animals weaned at booster. However, a favorable change in WBSF of $-0.047 \mathrm{~kg}( \pm 0.022 \mathrm{~kg})$ per unit of final antibody level $(P=0.03)$ in animals weaned at initial vaccination was identified. In a comparison of 2 comparable animals, which responded well to the vaccination with a final antibody level of 8 , this would lead to an expected $0.528 \mathrm{~kg}$ lower WBSF for the animal weaned at initial vaccination when compared to an animal weaned at booster vaccination.

Almost all carcass traits (HCW, CFAT, CREA, CKPH, MARB, YG, WBSF) exhibited no interaction

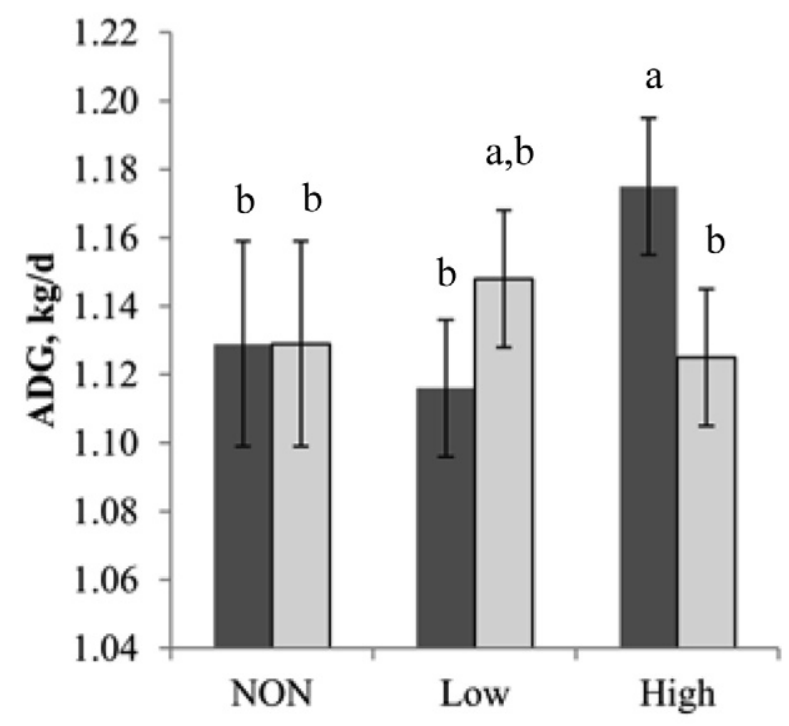

Response Group

\section{nWean@Initial $\square$ Wean@Booster}

Figure 4. Least squares means estimates for response level (non, low, and high) by weaning time (initial or booster) interaction effects on ADG $(\mathrm{kg} / \mathrm{d})$ in harvested animals. Least squares means with different letters are significantly different $(P<0.05)$.

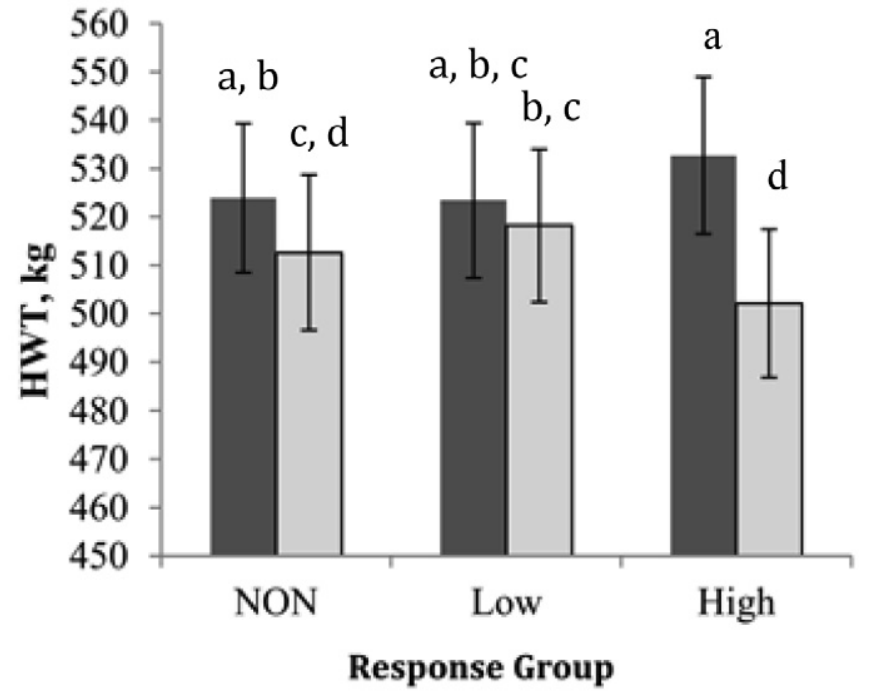

\section{nWean@Initial $\square$ Wean@ Booster}

Figure 5. Least squares means estimates for response level (non, low, and high) by weaning time (initial or booster) interaction effects on live harvest weight 1 to $7 \mathrm{~d}$ before harvest (HWT, $\mathrm{kg}$ ). Least squares means with different letters are significantly different $(P<0.05)$.

between overall response to vaccination and weaning timing or any main effects of weaning timing or overall response to vaccination, indicating little need to be concerned about animals repartitioning resources toward an immune response instead of carcass quality attributes. However, overall response interacted with weaning time $(P<0.05)$ to effect meat $\mathrm{pH}$ (Table 3$)$. Overall response did not have a significant association $(P=0.66)$ with $\mathrm{pH}$ in calves weaned at $\mathrm{I}$, with an estimate of 0.002 $( \pm 0.0042) \mathrm{pH}$ per overall response titer unit. However, in animals weaned at $\mathrm{B}, \mathrm{pH}$ changed $-0.010( \pm 0.0045)$ for each titer unit of overall response, which might indicate a decrease in dark cutter susceptibility in animals weaned at $\mathrm{B}$ with a high overall response.

The interaction between response level and weaning time only had a significant $(P<0.05)$ effect on HCW (Table 4). Although animals that had a high antibody response level and were weaned at I had numerically the heaviest HCW (Fig. 6), they were only significantly different from the high responders that were weaned at B. The difference within the high-responder group can be viewed as similar to that of Meyer et al. (2005). Additionally, low-responder calves that were weaned at booster vaccination were also significantly $(P<0.05)$ heavier than the high-responder cattle that were weaned at booster vaccination. In comparison, Step et al. (2008) observed no differences in HCW between weaned cattle vs. weaned and vaccinated or nonbackgrounded (no wean or vaccination history) cattle. Maes et al. (1998) showed no significant differences $(P=0.4116)$ in carcass traits between vaccinated and unvaccinated pigs. This study shows little effect of antibody level or responses 


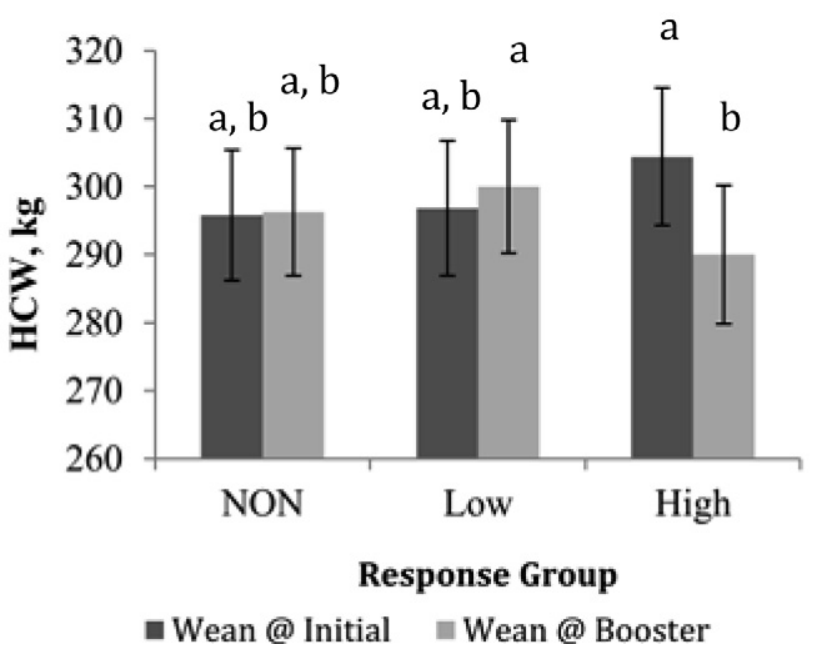

Figure 6. Least squares means estimates for response level (non, low, and high) by weaning time (initial or booster) interaction effects on $\mathrm{HCW}(\mathrm{kg})$. Least squares means with different letters are statistically different $(P<0.05)$.

to vaccination with traditional carcass quality traits, supporting the concept that increased antibody levels do not have deleterious consequences on carcass quality.

\section{Weaning Time Effects on Yearling Ultrasound Traits}

Since there were no interactions between response to vaccination traits and timing of weaning $(P>0.05)$ for any of the yearling ultrasound traits (Tables 2, 3, and 4), it is then appropriate to evaluate the effect of weaning timing on yearling ultrasound traits. The only yearling ultrasound trait affected $(P=0.01)$ by weaning timing was UPFAT. Calves that were weaned at booster vaccination had more UPFAT than calves weaned at initial vaccination $(4.42 \% \pm 0.22 \%$ vs. $4.24 \% \pm 0.22 \%$, respectively). In this study the calves weaned at initial vaccination (average $=139 \mathrm{~d}, \mathrm{SD}=32.6 \mathrm{~d}$ ) were weaned approximately $10 \mathrm{~d}$ earlier than the calves weaned at booster vaccination (average $=149 \mathrm{~d}, \mathrm{SD}=26.3 \mathrm{~d}$ ). Thus, this result is in contrast to early weaned vs. traditional weaned calf results on marbling reported by Meyer et al. (2005), where early weaned calves had higher marbling levels even though our difference in weaning age is much smaller than in their study.

\section{Weaning Time Effects on Performance Traits}

The timing of weaning significantly $(P<0.01) \mathrm{im}-$ pacted HWT in both the final antibody level and overall response models (Tables 2 and 3). Animals that were weaned at the time of the initial vaccination were 13.8 $\mathrm{kg}( \pm 3.3 \mathrm{~kg})$ heavier at harvest compared to animals that were weaned at the booster vaccination. This is a similar result to early weaned vs. normal weaned work by Meyer et al. (2005). Stressors, such as weaning, have been shown to have deleterious effects on animal performance (Blecha et al., 1984; Salak-Johnson, 2007). Step et al. (2008) showed that calves that were weaned before feedlot arrival had greater ADG, although no differences were shown between calves that were weaned for $45 \mathrm{~d}$ vs. calves that were weaned for $45 \mathrm{~d}$ and vaccinated with a modified live vaccine. Additionally, they showed that when calves were weaned and vaccinated, calves had increased BW in the feedlot compared to calves that were weaned without vaccination (Step et al., 2008). Even though the results of this study did not compare unvaccinated calves, increased harvest weight was observed in calves that were weaned at the initial vaccination compared to those weaned at booster vaccination.

\section{Weaning Time Effects on Carcass Quality Traits}

Although weaning time was associated with UPFAT at yearling stage, by harvest time, weaning time was no longer associated with MARB $(P>0.05$; Tables 2, 3, and 4). Although there is a lot of variation in MARB in the carcass traits across sexes (Table 1), it is important to note that this population of animals is being selected to increase marbling through the use of the yearling ultrasound data. Step et al. (2008) observed an increase in YG in calves that were weaned before feedlot entry or weaned and vaccinated. In contrast, in this study, weaning time did not affect YG $(P>0.05$; Tables 2,3 , and 4$)$.

Research has indicated that increased immune response may have negative effects on animal performance. A number of cytokines that have been identified as key regulators in immune response are also highly involved in metabolism pathways (Spurlock, 1997). However, our data supports the concept that antibody production is a quite different type of immune response, which may not have the large energy repartitioning associated with cytokine responses, as evidenced by the fact that neither the final antibody level nor the overall response to vaccination consistently negatively impacted animal performance. If increased antibody response was assumed to be a sign of effective protection, animals with higher response levels of antibodies did not consistently exhibit jeopardized performance to maintain that protection (Fig. 4, 5, and 6). Endsley et al. (2003) indicated that even if antibody levels do not increase in response to a vaccination in the presence of maternal antibody, animals do develop a cell-mediated immune response, developing memory cells, which help the animal endure a viral challenge when subsequently exposed.

\section{Conclusion}

Generally, final antibody level or overall response did not have a negative effect on yearling ultrasound, 
performance, or carcass quality traits. Calves weaned at the initial vaccination showed a disadvantage in UPFAT but an advantage in HWT. Calves with high final antibodies had higher levels of performance for YWT and URFAT. Interactions between antibody traits and timing of weaning stress during the vaccination protocol were identified. Calves weaned at initial vaccination had a desirable decrease in WBSF when their final antibody levels increased. Calves in the high-response group that were weaned at initial vaccination showed advantages for ADG, HWT, and HCW when compared to high responders weaned at booster vaccination. If antibodies from vaccination can prevent BRD outbreaks and increased antibody levels do not negatively affect yearling ultrasound, performance, or carcass quality traits, then BRD prevention through increased antibody levels may minimize economic losses associated with reduced performance and decreased carcass value from BRD.

\section{LITERATURE CITED}

Bauermann, F. V., E. F. Flores, and J. F. Ridpath. 2012. Antigenic relationships between Bovine viral diarrhea virus 1 and 2 and HoBi virus: Possible impacts on diagnosis and control. J. Vet. Diagn. Invest. 24:253-261.

Beef Improvement Federation. 2010. Guidelines for uniform beef improvement programs. 9th ed. http://www.beefimprovement. org/content/uploads/2013/07/Master-Edition-of-BIF-Guidelines-Updated-12-17-2010.pdf. (Accessed 14 Sept. 2013.)

Blecha, F., S. L. Boyles, and J. G. Riley. 1984. Shipping suppresses lymphocyte blastogenic responses in Angus and Brahman $\times$ Angus feeder calves. J. Anim. Sci. 59:576-583.

Downey, E. D., R. G. Tait Jr., M. S. Mayes, C. A. Park, J. F. Ridpath, D. J. Garrick, and J. M. Reecy. 2013. An evaluation of circulating bovine viral diarrhea virus type 2 maternal antibody level and response to vaccination in Angus calves. J. Anim. Sci. 91:4440-4450.

Endsley, J. J., J. A. Roth, J. Ridpath, and J. Neill. 2003. Maternal antibody blocks humoral but not $\mathrm{T}$ cell responses to BVDV. Biologicals 31:123-125.

Gardner, B. A., H. G. Dolezal, L. K. Bryant, F. N. Owens, and R. A. Smith. 1999. Health of finishing steers: Effects on performance, carcass traits, and meat tenderness. J. Anim. Sci. 77:3168-3175.
Griffin, D. 1997. Economic impact associated with respiratory disease in beef cattle. Vet. Clin. North Am. Food Anim. Pract. 13:367-377.

Holland, B. P., L. O. Burciaga-Robles, D. L. VanOverbeke, J. N. Shook, D. L. Step, C. J. Richards, and C. R. Krehbiel. 2010. Effect of bovine respiratory disease during preconditioning on subsequent feedlot performance, carcass characteristics, and beef attributes. J. Anim. Sci. 88:2486-2499.

Johnson, R. W. 1997. Inhibition of growth by pro-inflammatory cytokines: An integrated view. J. Anim. Sci. 75:1244-1255.

Kataria, R. S., R. G. Tait Jr., D. Kumar, M. A. Ortega, J. Rodiguez, and J. M. Reecy. 2011. Association of toll-like receptor four single nucleotide polymorphisms with incidence of infectious bovine keratoconjunctivitis (IBK) in cattle. Immunogenetics 63:115-119.

Maes, D., H. Deluyker, M. Verdonck, F. Castryck, C. Miry, A. Lein, B. Vrijens, and A. De Kruif. 1998. The effect of vaccination against mycoplasma hyopneumoniae in pig herds with a continuous production system. J. Vet. Med. A. 45:495-505.

Martin, S. W., E. Nagy, D. Armstrong, and S. Rosendal. 1999. The associations of viral and mycoplasmal antibody titers with respiratory disease and weight gain in feedlot calves. Can. Vet. J. 40:560-570.

Meyer, D. L., M. S. Kerley, E. L. Walker, D. H. Keisler, V. L. Pierce, T. B. Schmidt, C. A. Stahl, M. L. Linville, and E. P. Berg. 2005. Growth rate, body composition, and meat tenderness in early vs. traditionally weaned beef calves. J. Anim. Sci. 83:2752-2761.

Salak-Johnson, J. L., and. J. J. McClone. 2007. Making sense of apparently conflicting data: Stress and immunity in swine and cattle. J. Anim. Sci. 85(E. Suppl.):E81-E88.

Schneider, M. J., R. G. Tait Jr., W. D. Busby, and J. M. Reecy. 2009. An evaluation of bovine respiratory disease complex in feedlot cattle: Impact on performance and carcass traits using treatment records and lung lesion scores. J. Anim. Sci. 87:1821-1827.

Schneider, M. J., R. G. Tait Jr., M. V. Ruble, W. D. Busby, and J. M. Reecy. 2010. Evaluation of fixed sources of variation and estimation of genetic parameters for incidence of bovine respiratory disease in preweaned calves and feedlot cattle. J. Anim. Sci. 88:1220-1228.

Spurlock, M. E. 1997. Regulation of metabolism and growth during immune challenge: An overview of cytokine function. J. Anim. Sci. 75:1773-1783.

Step, D. L., C. R. Krehbiel, H. A. DePra, J. J. Cranston, R. W. Fulton, J. G. Kirkpatrick, D. R. Gill, M. E. Payton, M. A. Montelongo, and A. W. Confer. 2008. Effects of commingling beef calves from different sources and weaning protocols during a fortytwo-day receiving period on performance and bovine respiratory disease. J. Anim. Sci. 86:3146-3158. 